January 2014

\title{
An Analysis Of Abortion Demand In Pennsylvania 2000 - 2010
}

Guido Giuntini

How does access to this work benefit you? Let us know!

Follow this and additional works at: https://commons.und.edu/theses

\section{Recommended Citation}

Giuntini, Guido, "An Analysis Of Abortion Demand In Pennsylvania 2000 - 2010" (2014). Theses and Dissertations. 1654.

https://commons.und.edu/theses/1654

This Thesis is brought to you for free and open access by the Theses, Dissertations, and Senior Projects at UND Scholarly Commons. It has been accepted for inclusion in Theses and Dissertations by an authorized administrator of UND Scholarly Commons. For more information, please contact und.commons@library.und.edu. 
AN ANALYSIS OF ABORTION DEMAND IN PENNSYLVANIA 2000 - 2010

by

\title{
Guido Giuntini
}

\author{
A Thesis \\ Submitted to the Graduate Faculty \\ of the \\ University of North Dakota \\ in partial fulfillment of the requirements \\ for the degree of \\ Master of Science in Applied Economics
}

Grand Forks, North Dakota

August 2014 
This thesis, submitted by Guido Giuntini in partial fulfillment of the requirements for the Degree or ̂ Master of Science in Applied Economics from the University of North Dakota, has been read by the Faculty Advisory Committee under whom the work has been done and is hereby approved.

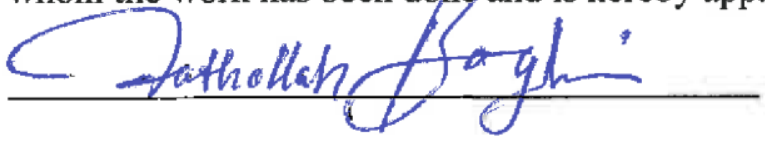

Dr. Fathollah Bagheri
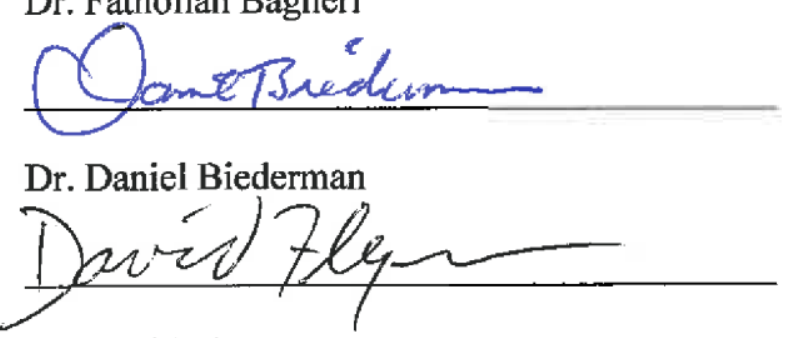

Dr. David Flynn

This thesis is being submitted by the appointed advisory committee as having met all the requirements of the School of Graduate Studies at the University of North Dakota and is hereby approved.

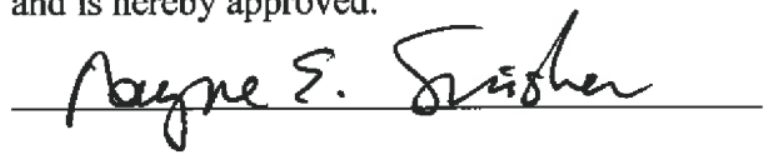

Dr. Wayne E. Swisher

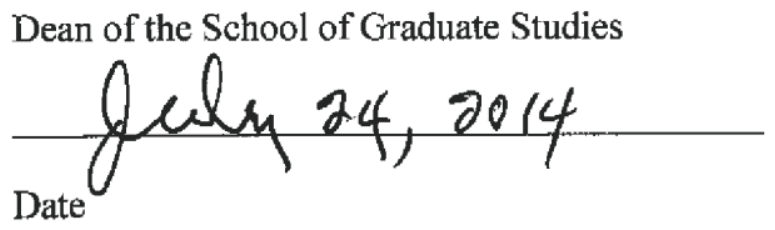

ii 


\section{PERMISSION}

Title An Analysis of Abortion Demand in Pennsylvania, 2000 - 2010

Department Applied Economics

Degree Master of Science in Applied Economics

In presenting this thesis in partial fulfillment of the requirements for a graduate degree from the University of North Dakota, I agree that the library of this University shall make it freely available for inspection. I further agree that permission for extensive copying for scholarly purposes may be granted by the professor who supervised my thesis work or, in his absence, by the Chairperson of the department or the dean of the School of Graduate Studies. It is understood that any copying or publication or other use of this thesis or part thereof for financial gain shall not be allowed without my written permission. It is also understood that due recognition shall be given to me and to the University of North Dakota in any scholarly use which may be made of any material in my thesis.

Guido Giuntini

July 11, 2014 
TABLE OF CONTENTS

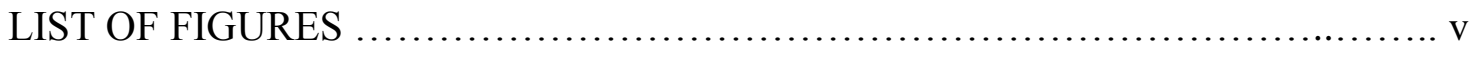

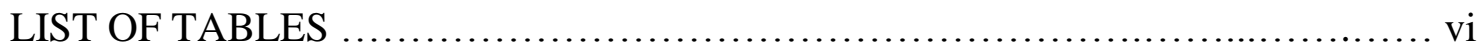

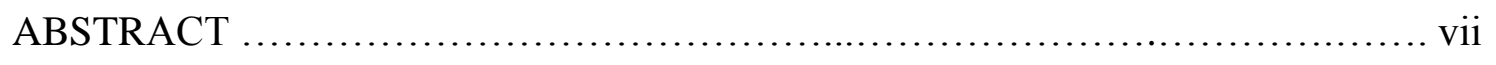
CHAPTER

I. INTRODUCTION ..................................... 1

II. LITERATURE REVIEW ............................ 6

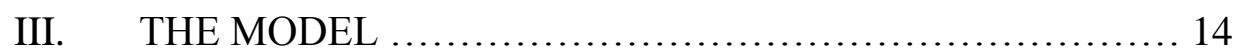

IV. GENERAL INFORMATION ABOUT ABORTION IN PENNSYLVANIA ....................................... 20

V. DATA AND ECONOMETRIC TECHNIQUE ................ 23

VI. RESULTS AND DISCUSSION .......................... 31

VII. CONCLUSION ..................................... 36

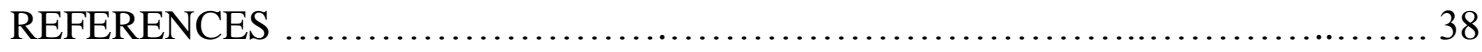




\section{LIST OF FIGURES}

$\begin{array}{lll}\text { Figure } & \text { Page }\end{array}$

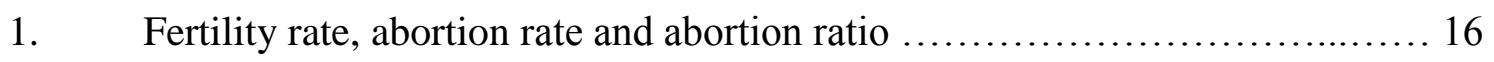

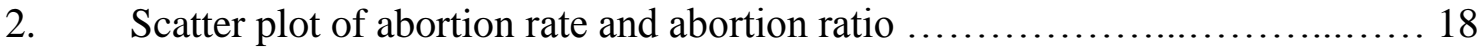

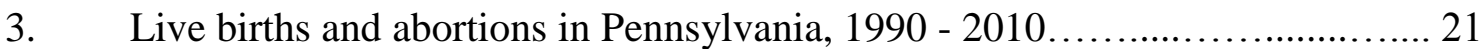

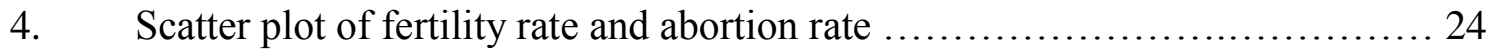




\section{LIST OF TABLES}

Table Page

1. Summary of price elasticities of abortion from previous studies.............. 11

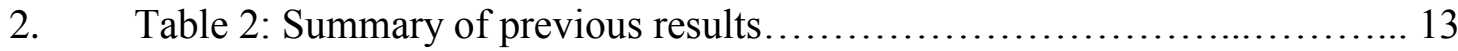

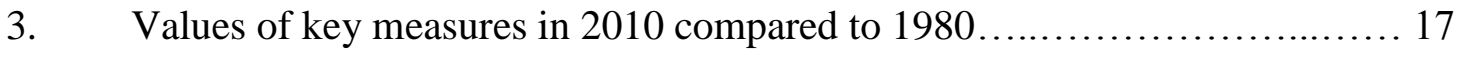

4. An overview of Pennsylvania abortion data............................ 20

5. Summary statistics of the variables included in the research in $2010 \ldots \ldots \ldots .29$

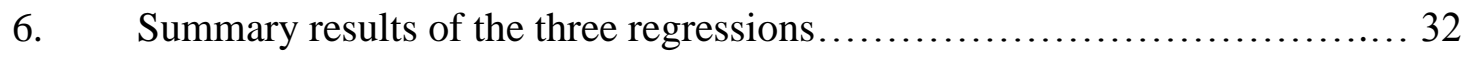




\begin{abstract}
In this paper I expand on previous research of the determinants of abortion demand to examine the demand for abortion in the specific case of Pennsylvania, where precise statistics are available for each county. The data considered is for the years 2000 and 2010, and allows for cross sectional and panel data analysis, specifically, firstdifference permitting to look at the effect of changes over time of specific explanatory variables. Careful attention is placed on variable selection techniques to avoid the use of low significance variables. The analysis allows controlling for price, as it is considered to be constant across the state, and for restrictive laws, as they are applied statewide. I also estimate the elasticity of demand for some key variables. The study introduces important demographic variables, such as fertility rate and the rate of women age 20 to 24 over women 15 to 49 . Changes in demographic variables appear to have the greatest effect on changes in the abortion ratio, more than economic or behavioral variables.
\end{abstract}


AN ANALYSIS OF ABORTION DEMAND IN PENNSYLVANIA 2000 - 2010

\section{CHAPTER I}

\section{INTRODUCTION}

Abortion is an issue charged with social, ethical and religious meanings. It is often contentious and the differences are not easily reconcilable although it has been part of human reproductive behavior since the dawn of civilization. Different societies have approached the event of unintended pregnancies in different ways. Recent the news is of a mass grave of over 800 dead children found in Ireland at a home for "fallen women" women who became pregnant without being married- dating between 1925 and 1961, when abortion was illegal in that country.

Abortion has been legal in the United States since 1973, although in recent years many states have begun to place bureaucratic hurdles to reduce access to the procedure. In this paper I will examine the issue in the attempt to parse out the effects of social, economic, and religious factors on abortion rates, controlling for cost and restrictive legislation. I will examine the determinants of abortion demand for the state of Pennsylvania using county data.

In his seminal 1976 book The Economic Approach to Human Behavior, Nobel Prize winner economist Gary Becker lays out a theory of the demand for children based on his revolutionary 1960 article "An Economic Analysis of Fertility". In it, the University of Chicago economist attempts to explain human behavior in areas traditionally belonging to psychologists, sociologists and anthropologists based economic 
analysis and utility theory. He shows how families base the decision of how many children to have on rational economic analysis, namely opportunity cost and cost-benefit analysis. Historical demographic trends are in part explained by changes in the cost and benefit of raising children compared to other goods. Families can control the number of children in several ways, the most common being age of marriage, abstinence, contraception, and abortion. The recent increase in the number of children born out of wedlock, reaching $40.8 \%$ of all births in 2010, signals a shift away from the postponement of the age of marriage as a way to decrease the number of children. The existence of forms of family planning, including infanticide, has been demonstrated by anthropologists and archaeologists. The rise of the field of Cultural Anthropology, brilliantly and convincingly summarized by Marvin Harris in his 1979 book Cultural Anthropology, makes a compelling case for looking at cultural shifts in material terms and field observations; the economist's approach. Harris calls this approach the "etic" view. He moves anthropology away from the traditional approach, what Harris calls the "emic" viewpoint, or the knowledge represented by the explanation of the behavior given by the subject observed.

As an example, Harris cites the Hindu farmers of the Trivandwan district in the state of Kerala in southern India. Although every farmer interviewed cited the Hindu prohibition of harming cows, female cattle outnumber male by a ratio of 1 to 0.67 . Because of its geographical formation, in Trivandwan there is little demand for male traction animals, as opposed to Uttar Pradesh, where different ecological and economic conditions are present and where the male/female ratio is reversed, being 0.5 to 1 . Farmers do not directly kill the unwanted gender, but they slightly favor the needed kind, 
altering the natural male to female ratio in the direction more favorable to their material needs.

Moving back to Becker's analysis, his research showed why an increase in income did not give way to an increase in the number of children, but a decrease. This finding is contrary to what would be expected by a simplified version of economic theory. Although income has increased, the cost of children has also increased and as income raises families increase the quality of children and decrease the number of children, leaving total expenditures on children unchanged.

Harris (1979) explains the same concepts this way for the United States, When there was an agrarian homesteading, frontier infrastructure, families were large and women's role as mother and unpaid domestic laborer emphasized. With urbanization and the increasing cost of reproduction relative to benefits expected from children, women began to "raise their consciousness," demanding entrance to the general employment market on an equal basis with males. (73)

In recent years several researchers have focused their attention to an analysis of the prevalence of pregnancy termination in the United States. Abortion is one of the means by which women have controlled the number of children. Although some states had already legalized abortion to various degrees beginning a few years earlier, in 1973 the Supreme Court of the United States found that the right of a woman to decide whether to terminate a pregnancy is a constitutional right. In recent years, many states have moved to restrict access to abortion both with a demand-side approach, including 
required waiting periods, decreased funding and mandated information sessions; and a supply-side approach with greater and more burdensome regulations imposed on abortion providers. For example, North Dakota is poised to lose its last remaining clinic, and pending legislation in Texas is going to close up to $80 \%$ of its clinics. Anecdotal evidence exists that women are already turning to illegal methods to obtain abortions, often by self-medicating, or crossing borders with more frequency to nearby countries with easier access to providers or medications. Economic theory, history and empirical evidence tell us that simply making a product or a service illegal does not eliminate its existence. According to several studies, illegal abortion was quite common in pre-Roe-vs.-Wade America. Estimates varied between 200,000 and 1,000,000 per year. No estimate exists on illegal pregnancy terminations specifically referring to the pre-1973 state of Pennsylvania, which is the state considered in this paper.

My research will examine and improve the approach used to evaluate the demand for abortion in the United States by examining the abortion data for the state of Pennsylvania. I will focus on economic, social, and behavioral explanatory variables in an attempt to explain differences in abortion rates across different counties controlling for price and restrictive laws which are constant across the state. Previous research focuses on data by state, which have different laws governing access to abortions. Studies consider as independent variable either the abortion rate, which is the number of abortions per 1000 women or the abortion rate, which is the number of abortions per 1000 live births. The dependent variable is then regressed against a set of explanatory variables encompassing a list of economic, social, and geographical factors. The data is 
generally available through the Center for Disease Control and Prevention (CDC) and The Guttmacher Institute, the leading institution on reproductive matters.

In this analysis, I will use the exhaustive abortion data collected by the Pennsylvania Department of Health for each of the 67 counties in Pennsylvania to estimate the demand for abortion in the state in 2000 and 2010 and the changes between the two years. This approach allows me to control for price. Previous analysis always uses a statewide average price for an abortion. The cost is generally not available by provider, and varies wildly according to the type of procedure. The cost of the procedure is considered constant across the state. Careful attention will also be given to variable selection techniques in order to minimize the inclusion of low significance variables.

The choice of each variable is carefully explained. Each one is selected based on previous studies and economic theory, in an attempt to minimize the risk of omitted variable bias and cover all social, economic, behavioral, and geographical factors that help explain the decision of a woman to terminate a pregnancy. 


\section{CHAPTER II}

\section{LITERATURE REVIEW}

Although the scope of this paper is not to examine abortion in the years before legalization, a brief review of the techniques used, and especially of the results is important to show the size of the phenomenon in an epoch in which it was illegal, when obtaining it had high economic, social, psychological costs and great health risks. The high incidence of the phenomenon when faced with high costs is an indication of low price elasticity. There are no studies that look at illegal abortions in recent years, and all abortions are assumed to be legal and recorded, although some states are better than others at keeping track of the exact numbers. One reason why I chose Pennsylvania for this analysis is its detailed and precise recordkeeping.

Researches have attempted to estimate illegal abortions in the United States in the years before Roe v. Wade, and their estimates vary wildly. Calderone (1955) estimates the number to be between 200,000 and 1,200,000. Cates and Rochat (1976) estimate there were about 130,000 illegal pregnancy terminations in 1972 , the year before the Supreme Court decision to legalize abortion, when already the procedure was legal in some states, including New York. For comparison, and keeping in mind that since then the population of women age 15-44 has increased, approximately 1,060,000 legal abortions were performed in 2011 in the United States.

There are several ways used to estimate induced abortions (whether illegal or legal in cases where the recordkeeping system is not reliable). They are extensively 
reviewed by Rossier (2003), but they can be broadly grouped into three main categories: surveys, experts' opinion, and calculations based on fertility/mortality statistics. Abernathy at al. (1970) used the survey method in urban North Carolina to estimate the number of abortions nationwide, which they placed at 829,000 in 1967. Cates and Rochat (1976) use abortion related mortality to extrapolate the number of abortions performed. Foreit and Norman (1992) use a variation of a method developed earlier, called the Residual Method, first proposed by Bongaarts in 1978. The method is based on a theoretical level of maximum biological fertility multiplied by indexes of determinants reducing fertility to obtain the observed total fertility rate. One of the determinants is the abortion rate; the others are observed fertility, contraceptive use, age of marriage, and post-partum infertility. If all other values are known, it is possible to solve for the abortion rate. Bongaarts (p.106) calls these direct determinants "intermediate fertility variables", and considers them to be affected by indirect determinants, specifically "socioeconomics, cultural, and environmental variables". The total natural fecundity rate, which is the theoretical maximum number of births per woman in absence of any obstacle to procreation, is calculated by Bongaarts to be around 15. In practice, the observed rate is much lower. The value for the United States was 2.88 in 1965 and 2.05 in 1980. Foreit and Norman (1992), used the method to estimate abortion rates for Belo Horizonte, Lima, and La Paz, where reliable records do not exist.

Each one of the methods suffers from estimation biases and weaknesses, which are discussed in Rossier (2003). Even though the price of an illegal abortion was quite high, not only in monetary terms, but for possible health, legal and social consequences, it appears that women were nonetheless willing to go to great lengths to terminate 
unwanted pregnancies. The implicit message is that the demand for abortions is fairly inelastic.

In 1973 the Supreme Court of the United States legalized abortion recognizing that states have the right to regulate how it is administered within certain parameters. In the first trimester, a woman must have full access to abortion; some regulations could be implemented in the second trimester, while in the third trimester abortion can be restricted except to protect the health of the woman.

Several studies have attempted to estimate the determinants of the demand for abortion, mostly focusing on price, restrictive state laws, labor force participation, income, education, marital status, religiosity, geographical location, Medicaid funding, the level of urbanization, and other demographic variables. Previous research on abortion demand uses mainly aggregate (state-wide) data from each of the fifty states and the District of Columbia with simple OLS regression, panel data analysis and, more recently, to circumvent the problem of the endogeneity of abortion price, with the use of instrumental variables. Either the abortion rate or the abortion ratio is treated as the dependent variable on a vector of variables including some or all of those listed above.

There are some problematic aspects in the previous analysis that this research attempts to correct. One is the level of data aggregation. The reliability of data collection varies state by state, and interstate abortions are sporadically recorded. Often, although less in recent work, not enough attention is paid to variable selection techniques in model determination, and the dangers or omitted variable bias -as well as possible endogeneityare often overlooked. 
A challenging aspect of considering abortion price is that the only available data is the average price by state. Rothstein (1992) explains that, "PRICE, an explanatory variable, is the average cost of an abortion performed in the first trimester in a nonhospital facility with local anesthesia for each state and the District of Columbia" (56). Providers charge different prices and most of them have private grants and funds that cover some of the expenses for low-income patients. Moreover, the price varies with the type of procedure and generally increases in later stages of the pregnancy, although over $80 \%$ of all abortions are performed in the first trimester and are in nonhospital facilities. Researchers admit that the measure of price is imprecise, as there is no reliable and nation-wide collection of abortion prices, but only estimates and price ranges collected by the Alan Guttmacher Institute. Variations in price should be adjusted for regional cost of living, adjusted for the average week of pregnancy at which termination occurs, and the availability of funds. In addition, it should be treated as an endogenous variable, which would require the use of instruments. Medoff (2012), for example, uses as instruments to control for endogeneity of price i) the number of nurses per 100,000 women of childbearing age; ii) the number of physicians non OB/GYN per 100,000 women; and iii) the number of hospitals.

Medoff proposes the following theoretical model. The number of abortions is assumed to be a function of the abortion cost and the number of unintended pregnancies, which in turn are assumed to be a function of the cost of an abortion and the effectiveness of other contraceptive methods. He defines as A the number of abortions, $\mathrm{C}$ as the cost of an abortion, $\mathrm{P}$ is the number of pregnancies and $\mathrm{Z}$ a vector of alternative contraceptive methods. 


$$
A=f(C, P(C, Z))
$$

$\mathrm{C}$ is not only the direct cost of an abortion, but it includes indirect costs such as restrictive abortion laws. Following the fundamental law of demand, $\delta \mathrm{A} / \delta \mathrm{C}<0$ and $\delta \mathrm{A} / \delta \mathrm{P}>0$; an increase in the cost of an abortion decreases the number of abortions and an increase in pregnancies increases the number of abortions.

From (1), the increase of the cost of an abortion is:

$$
\frac{d A}{d C}=\frac{\partial A}{\partial C}+\frac{\partial A}{\partial P} \frac{\partial P}{\partial C}
$$

The net effect on the number of abortions with an increase in $\mathrm{C}$ depends on the stage in which women factors the increased cost. If the cost $\mathrm{C}$ is factored after the pregnancy, then the second term in (2) is 0 , and an increase in $\mathrm{C}$ reduces the number of abortions leaving the number of pregnancies unaffected. If women treat abortion as birth control method, on the other hand, and increase in $\mathrm{C}$ will reduce the number of pregnancies. Medoff and other researchers base their analysis the assumption that abortion is a normal good and that it is used as contraceptive method: two testable hypotheses.

Table 1 shows a summary of price elasticities calculated from previous research. It varies from very inelastic -0.348 to quite elastic, -2.3 . The elasticity appears to be negative in every case. As shown in table 2, not all studies find a positive sign for the income coefficient, and the values are generally quite low. Abortion appears indeed to be a normal good, but, there are signs that changes in income have limited effects on the number of abortions. 
Table 1: Summary of price elasticities of abortion from previous studies

\begin{tabular}{|lll|}
\hline Author & Year & Price Elasticity \\
Medoff & 1988 & between -.70 and -.99 \\
Garbacz & 1990 & -.68 \\
Rothstein & 1992 & -.348 \\
Medoff & 1997 & -.81 \\
Medoff & 2008 & -1.16 \\
Medoff & 2012 & -2.3 (for unintended pregnancies) \\
\hline
\end{tabular}

Medoff (2008) addresses the possible reasons why the price of an abortion, although small as compared with the cost of raising a child, seems to have such strong influence on the number of abortions. The first explanation is the lack of "a control variable that includes the emotional costs of an abortion (e.g., regret, humiliation, shame, guilt)." (343) He notes that a possible way to measure it is by the number of restrictive laws implemented in a specific state.

Second, the abortion demand equation does not control for the cost of raising a child, although it might in part be incorporated in other variables. Finally, there are possible effects of demographic changes in the composition of women of childbearing age. All cases would result in an upward bias of the estimated effect of the abortion price.

Another concern is the limited attention to paid variable selection techniques. Too often variables with low significance level are included in the model. For example, Medoff (2008) includes 15 explanatory variables in his model for the estimation of the abortion rate, eight of which are not significant at the $10 \%$ level. The variation in price 
elasticity -from inelastic to very elastic- as well as the variation of the level of significance of the coefficients across different studies is a sign that further research is necessary.

Table 2 shows a summary of the results of previous research and it includes the following studies: Medoff 2012, 2008, 1997 (indicated by M 2012, M 2008, and M 1997 respectively); Snarr and Edwards 2009 (S 2009); Rothstein 1992 (R 1992); Garbacz 1990 (G1990). The table gives the sign of the coefficient and (*) represents significance at the $5 \%$ level.

Price and income are the only variables included in most studies and significant across the board. The income sign, though, is not constant across the studies; Medoff (1997) finds it to be negative. This inconsistency can be explained by the fact that although higher income is generally associated with lower fertility rates, it is also associated with higher contraception use.

Access to Medicaid funding seems also to have a positive effect, although not always with a high level of significance. The positive (increasing) effect on abortion rate of the Catholic religion found by Medoff (1997) is among the most counterintuitive results, as it is the generally low effect of education. As expected, the ease of access to a clinic has a positive effect, although such measurement is of dubious determination at the state level and fails to account for cross-state procedures.

The only explanatory variable that seems to hold consistent results is the most problematic and least reliable in terms of data collection. In this study I attempt to control for price and restrictive laws by considering each individual county in the state of Pennsylvania. Restrictive laws are the same across the state and have not changed in 
Pennsylvania in the period considered, and the price is considered to be the constant across the state.

Table 2: Summary of previous results

\begin{tabular}{|c|c|c|c|c|c|c|}
\hline Variable & M 2012 & S 2009 & M 2008 & M 1997 & R 1992 & G 1990 \\
\hline Price & $-(*)$ & & $-(*)$ & $-(*)$ & $-(*)$ & $-(*)$ \\
\hline Income & $+(*)$ & $+(*)$ & $+(*)$ & $-(*)$ & $+(*)$ & $+(*)$ \\
\hline Medicaid & & + & & $+(*)$ & $+(*)$ & + \\
\hline Urban & & $+(*)$ & & & & $+(*)$ \\
\hline Minority & & & & & & + \\
\hline Favorable & & & & $+(*)$ & & + \\
\hline Education & & - & $-(*)$ & + & - & - \\
\hline Clinic & & $+(*)$ & & & & $+(*)$ \\
\hline Mand. Couns. & + & & - & & & \\
\hline Two-visit & - & & & & & \\
\hline Labor force & & & + & + & & \\
\hline Married & & & - & & $-(*)$ & \\
\hline Poverty & & + & & & & \\
\hline Religion & & & - & $+(*)$ & & \\
\hline Unempl. & & + & & $-(*)$ & $+(*)$ & \\
\hline West & & & & & $+(*)$ & \\
\hline Divorce rate & & & & & $+(*)$ & \\
\hline Republican & & - & & & & \\
\hline R-squared & 0.78 & 0.88 & 0.65 & 0.66 & 0.87 & 0.77 \\
\hline
\end{tabular}

Finally, in my study I introduce a new explanatory variable that has been overlooked before, the total fertility rate. The rationale for the introduction of this variable will be given in the next section. 


\section{CHAPTER III}

\section{THE MODEL}

Gary Becker (1978) sets up an economic framework for understanding the nature and the considerations in family planning. He distinguishes between the desired quantity and quality of children. A family must determine not only how many children to have, but also how much to spend on them. According to his model, “... a rise in the long-run income would increase the amount spent on children." (118) Assuming children are not inferior goods, a rise in income will increase the amount spent on children, but the increase does not necessarily mean an increase in the number of children, as it could also mean an increase in the amount spent on each child (increased quality). Empirical evidence cited by Becker shows decreased fertility as income increases with a slight uptick of the number of children for higher earners. He finds that, in general, an increase in income reduces the desire to have children, but it augment the desire to increase the quality of children. At the macro level, evidence shows a strong inverse correlation between economic growth and fertility rates, especially for developing economies. Wealthier populations have fewer children but spend more on each one. Following Becker's reasoning, the desired number of children changes with changes in economic factors, and the fertility rate is a factor determining the number of abortions performed.

Maximum fecundity is the theoretical maximum number of children a woman can bear over a lifetime, while the total fertility rate is the number of children a woman would have over a lifetime at current age specific rates. Often the fertility rate is interchanged 
with the birth rate, which is the number of children born for 1000 women of childbearing age. Although natural maximum fecundity is considered to be around 15, the total fertility rate in the United States was 2.88 in 1965 and 1.9 in 2010. The implication is that family planning played a big role in women's life and that the opportunity cost of having many children drove families to limit the number of offspring even in the presence of a ban on abortion. Pregnancy termination is not the only method used to reduce total fecundity. Bongaarts (1978) calls the family planning methods intermediate fertility variables.

Bongaarts proposes a list of intermediate fertility variables as follows:

I - Exposure factors

1. Proportion married

II - Deliberate marital fertility control factors

2. Contraception

3. Induced abortion

III - Natural marital fertility factors

4. Lactational infecundability

5. Frequency of intercourse

6. Sterility

7. Spontaneous intrauterine mortality

8. Duration of the fertile period

The intermediate fertility variables are a function of social norms and economic factors, and given the difficulty of finding reliable data for the intermediate variables, social and economic factors are the ones considered in most studies. 
There are two candidates for independent variable. One is the abortion rate, which represents the number of abortions per 1000 women of childbearing age 15-44 (or sometimes 49); the other is the abortion ratio, which represents the number of abortions per 1000 live births. Although the two measures are quite similar, they can differ. Historically though, they tend to be quite highly correlated as shown in figure 1, with a correlation of 0.9865 .

Figure 1: Fertility rate, abortion rate and abortion ratio 1980 - 2009; indexed, $1980=100$

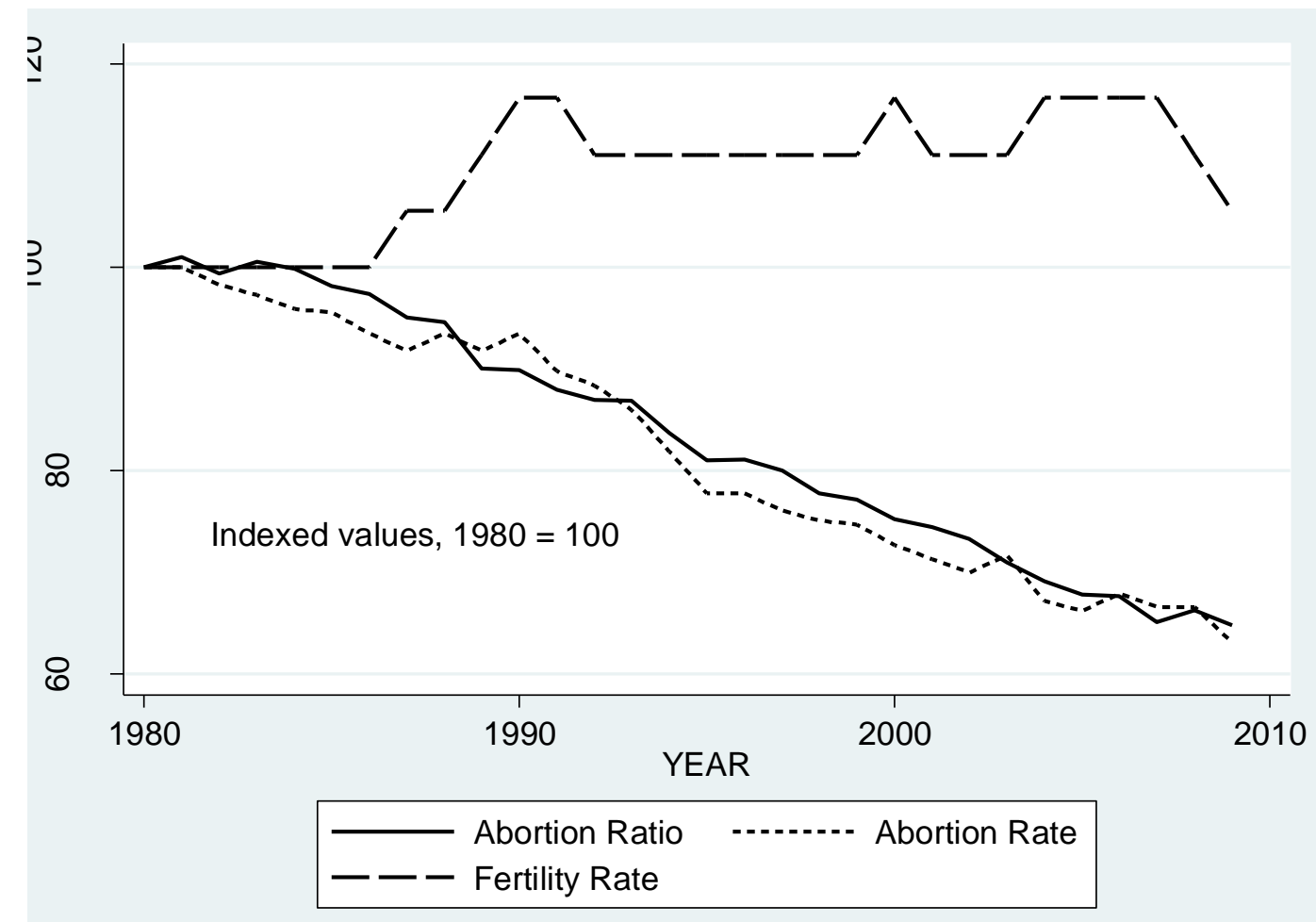

Figure 1 also shows the fertility rate for the United States in the same period compared with the abortion rate and the abortion ratio. While abortion rate and abortion ratio show a marked decreasing trend, the total fertility rate tends to be quite stable over the period considered, oscillating between 1.8 and 2.1 children per woman. 
Table 3 gives a sense of some changes that occurred in some key variables between 1980 and 2010. Beside the variables mentioned above, it also shows the female labor force participation rate; the percentage of births to unmarried mothers, which more than double in the period considered; and the percentage of women who declare they have used contraception. This last variable is difficult to measure and surveys are generally unreliable. In the study I use other proxy variables to control for contraceptive use.

Table 3: Values of key measures in 2010 compared to 1980

\begin{tabular}{|lll|}
\hline Birth rate & 64.1 & $(1980-68.4)$ \\
Abortion ratio & 217 & $(1980-359.2)$ \\
Female labor force participation rate & $58.10 \%$ & $(1980-51.5 \%)$ \\
Births to unmarried mothers & $40.80 \%$ & $(1980-18.4 \%)$ \\
Contraceptive use & $97 \%$ & $(1980-90 \%)$ \\
\hline
\end{tabular}

There are two candidates for dependent variable: the abortion rate and the abortion ratio. The abortion rate measures the number of abortions per 1000 women of childbearing age (usually between ages $15-44$ or 49 ), while the abortion ratio measures the number of abortions per 1000 live births. Most studies use the abortion rate as the dependent variable, although some do use the abortion ratio or both.

The correlations between the two values for the state of Pennsylvania in the periods considered and the first-differencing are respectively: 0.9858 in 2000; 0.9662 in 2010; and 0.9621 for the first-differencing. The high correlation is clearly visible in figure 2. The implication is that the two measures for the most part change in the same 
direction. Following Snarr and Edwards (2009), this study uses the abortion ratio as the dependent variable. The reason for the choice is that the abortion ratio is more reliable as it is computed from vital statistics, while the abortion rate is computed by using estimates of annual state, or in our case, county population.

Figure 2: Scatter plot of abortion rate and abortion ratio

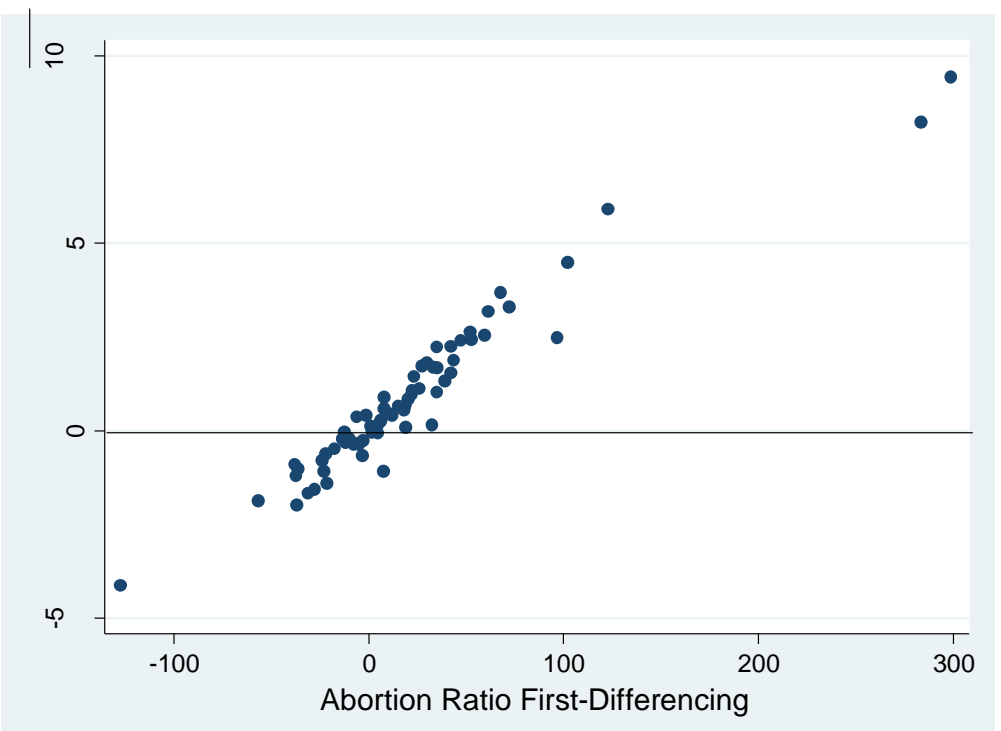

Given the fact that the price of an abortion is constant across the state, as are state laws governing access to the service, the abortion ratio, A for county $i$ at time $t$ is a function of the number of children desired $\mathrm{C}$, a vector of economic conditions $\mathrm{E}$, a vector of social conditions $\mathrm{S}$, and a vector of behavioral factors, B.

$$
A_{i, t}=f\left(C_{i, t}, E_{i, t}, S_{i, t}, B_{i, t}\right)
$$

The function can be approximated by an additive linear function, where the abortion ratio can vary between 0 , when there are no abortions, and $\infty$.

Unlike Medoff's model, which assumes abortion to be a normal good, and since by using county data I can control for price and state laws, the signs of the relationships 
need to be identified by empirical analysis. When describing the variables, I will use economic theory to assume the expected signs of the parameters.

Following, among others, Gober (1988) and Rothstein (1992) the model first estimates the parameters using OLS for 2000 and 2010. Since price is constant, the problem of endogeneity is not present as regard to price.

The linear model for 2000 and 2010 is estimated with OLS,

$$
y_{i=} \beta_{0}+\beta_{1} X_{1}+\beta_{2} X_{2}+\cdots+\beta_{n} X_{n}+\varepsilon_{i}
$$

where $y_{i}$ is the abortion ratio, $X_{1}, X_{2}, \ldots, X_{n}$ the determinants of abortion demand which are explained in detail in the next section, $\beta_{0}, \beta_{1}, \beta_{2}, \ldots, \beta_{n}$ the coefficients, and $\varepsilon_{i}$, the error term.

Then, following Medoff (1997, 2008, and 2012) I will use panel data analysis, specifically first-differencing (fixed effects) to determine the effects of changes over time. Assuming the presence of differences across counties that are constant but not observed, first-differencing eliminates those effects. Calling $Z_{i}$ a vector of the omitted variables,

$$
\begin{aligned}
& Y_{i, 1}=\beta_{0}+\beta_{1} X_{i, 1}+\beta_{2} Z_{i}+u_{i, 1} \\
& Y_{i, 2}=\beta_{0}+\beta_{1} X_{i, 2}+\beta_{2} Z_{i}+u_{i, 2}
\end{aligned}
$$

where $\beta_{1}$ and $\beta_{2}$ are a vector of the coefficients, and $X_{i}$ a vector of the explanatory variables.

By taking the first difference,

$$
\begin{gathered}
Y_{i, 2}-Y_{i, 1}=\beta_{1}\left(X_{i, 2}-X_{i, 1}\right)+u_{i, 2}-u_{i, 1} \\
\Delta Y_{i}=\beta_{1} \Delta X_{i}+\Delta u_{i}
\end{gathered}
$$

The model allows to cross-check the results for consistency. 


\section{CHAPTER IV}

\section{GENERAL INFORMATION ABOUT ABORTION IN PENNSYLVANIA}

The Pennsylvania Department of Health collects and reports the official numbers on abortion in a detailed report available online. The assumption is that, the procedure being legal, there are no illegal (performed out of authorized locations) or self-induced abortions. The data used here does not record out of state abortions on Pennsylvania residents, and it does not include procedures performed on out-of-state residents. The highest number of abortions was performed in 1980 with 65,777 procedures, while the lowest recorded was in 1999, 34,494 procedures. Over $90 \%$ of the procedures performed occur in the first 14 weeks of pregnancy.

Table 4: An overview of Pennsylvania abortion data

\begin{tabular}{|llc|}
\hline & 2000 & 2010 \\
Population & $12,281,054$ & $12,702,379$ \\
Live births & 145,874 & 142,370 \\
Abortions & 33,901 & 35,277 \\
Abortion ratio (x1000 live births) & 232.4 & 247.8 \\
Abortion rate (x 1000 women 15-44) & 13.2 & 14.4 \\
\hline
\end{tabular}

It is important to point out that the data used in this analysis refers only to Pennsylvanian women seeking to terminate a pregnancy in-state, since county data is 
only available in this case. In 2010, according to CDC data, 2402 residents of Pennsylvania terminated a pregnancy out of state. Given the small population size of some rural counties, even a small number of women from rural areas seeking abortions out of state might skew the results.

In Pennsylvania, since 1989, there are four provisions limiting access to abortion: a 24-hour waiting period between a positive pregnancy test and the procedure; a mandatory reading of state-issued material; parental permission required for women under the age of 18; and a ban on the use of federal or state funds at any stage of the procedure. A fifth one-spousal notification- was struck down by the Supreme Court.

Figure 3: Live births and abortions in Pennsylvania, $1990-2010$. Indexed, $1990=100$

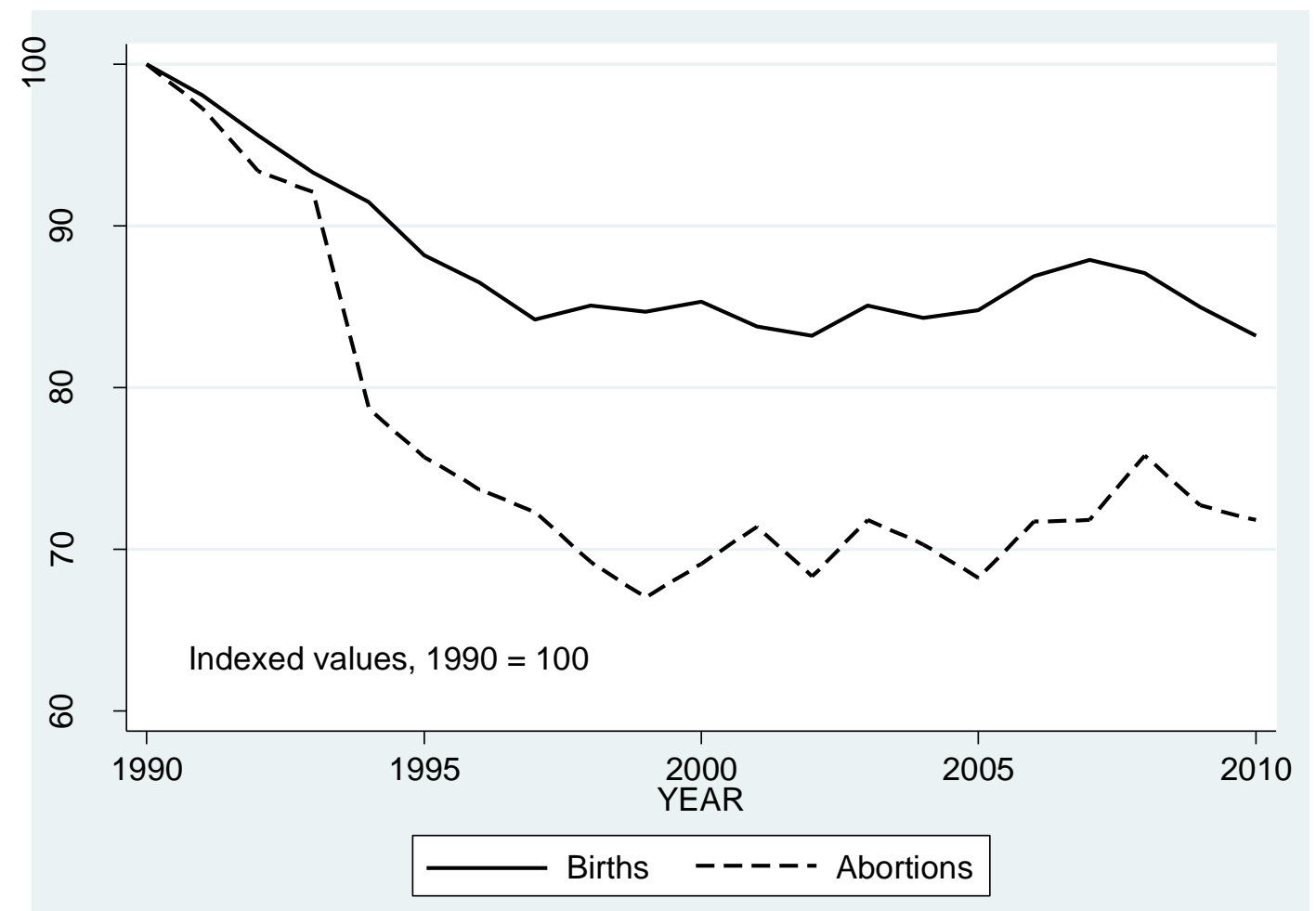


Figure 3 shows the trend for the number of live births and the number of abortions between 1990 and 2010. The respective rates, both calculated on the same base of the number of women of childbearing age, would show the same trend. In the mid-90s the trends started to diverge, and since then they seem to follow the same pattern. The correlation is quite high, 0.9625 .

According to the Guttmacher Institute, in 2010, there were 47 abortion providers in Pennsylvania; 20 of those were clinics. In 2010, 87\% of Pennsylvania counties had no abortion clinic. $49 \%$ of Pennsylvania women lived in these counties. Some rural Pennsylvania counties are quite far from the nearest clinic, and the restrictive laws mentioned above can place a relative high opportunity cost on women living in those areas.

In 2000 the gap between the US and Pennsylvania abortion rates was 7 abortions per 1000 women, while it shrunk to 1.8 in 2010. 


\section{CHAPTER V}

\section{DATA AND ECONOMETRIC TECHNIQUE}

This research uses data for each of the 67 Pennsylvania counties to estimate the factors that can influence the demand for abortion. The data used in this paper is available from the Pennsylvania Department of Health, the Guttmacher Institute, the Pennsylvania State Board of Elections, the Association of Religion Data Archive (ARDA), and the Census Bureau.

Having data available for 2000 and 2010 allows for a comparative analysis of different techniques and different time periods. In each case, to avoid the use of irrelevant variables, careful attention will be paid to variable selection techniques. Specifically, I will use stepwise forward selection with a cutoff or 0.3 .

Not included in the data, for lack of detailed information regarding specific counties of residence, are out-of-state abortions. The Center for Disease Control and Prevention reports the number of out-of-state abortions. In 2010, a total of 2402 abortions were performed on Pennsylvania residents by facilities in other states; specifically, 1060 in New Jersey, 728 in New York, 491 in Delaware, and 123 in Ohio. These numbers represent the $6.8 \%$ of total abortions performed on Pennsylvania women, and a small percentage of the total. Nonetheless, they can have a great impact on abortion rate and ratio if the women interested live in rural counties with small populations and far from the cities where the clinics are located, where even few abortions would considerably 
alter the values of the abortion rate and the ratio. For examples, in the year 2000, 1256 women of reproductive age lived in Cameron County, and five were the recorded abortions. The county is located in the northern part of the state, closer to facilities in New York State than to the ones in Philadelphia. It easy to see how even few women seeking to terminate a pregnancy out of state could substantially alter the values of abortion rate and abortion ratio for that county.

In terms of variable selection, this study introduces two variations from previous research. One is the ability to control for price and restrictive legislation, as discussed in a previous section. The other is the introduction of the fertility rate. At an intuitive level, it might appear logic to assume a strong, inverse correlation between fertility rate and abortion rate and ratio. The general fertility rate measures the number of live births per 1000 women of childbearing age. The correlation with the abortion rate is expected to be negative, and in fact it is, being respectively -0.0227 in $2000 ;-0.12$ in 2010 ; and -0.4129 for the first-differencing. As shown in figure 4, the correlation is less marked than one might assume, and often the two measures vary in the same direction.

Figure 4: Scatter plot of fertility rate and abortion rate

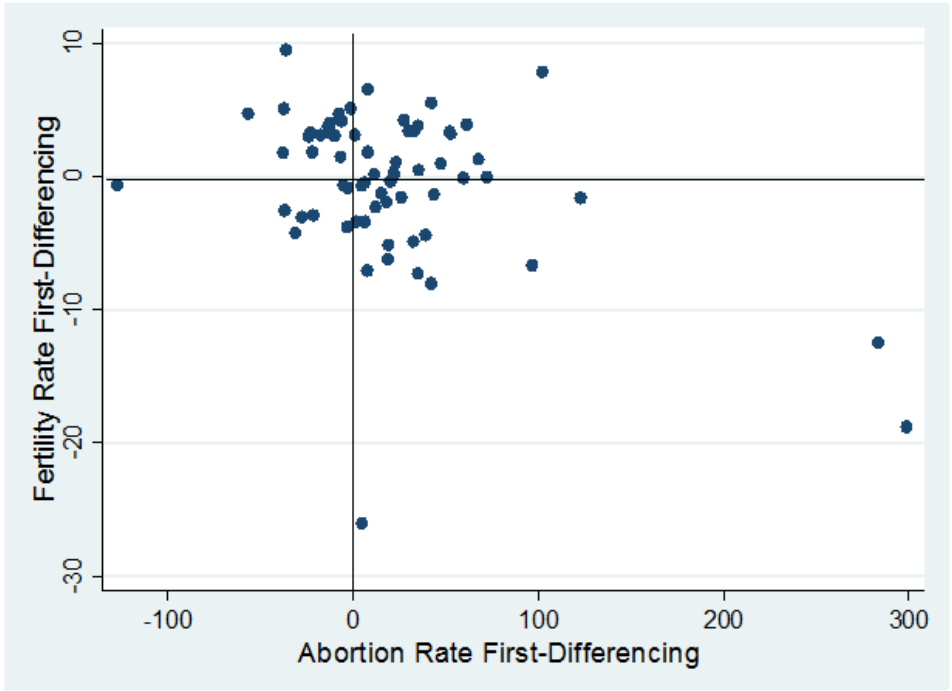


If, on the one hand, using data for individual counties in a single state alleviates some of the problems connected with high levels of aggregation and allows to control for the absence of providers in the county -a fact that increases the opportunity cost of the procedure- on the other hand it does not allow for the geographical breadth of countrywide analysis, and the results cannot be easily generalized.

The dependent (explanatory) variables have been chosen based on previous research, economic theory, and availability and reliability of data. The choice and rationale for each variable is explained below, as it is the expected a priori sign of the coefficient.

Fertility rate. The fertility rate is not usually considered as a dependent variable in economics estimations of the demand for abortion, but it is, in my opinion, an important factor that captures changes in desire for women to bear children. I expect the sign of the coefficient to be negative.

Median household income. Most previous empirical research and theoretical models include income. The expected sign of the relationship is not a priori obviously clear, as the demand for children decreases as income grows, as quality of children become more important than quantity, increasing the opportunity cost of having children. On the other hand, higher income is associated with higher education, access to contraception but also financial ability to afford abortion services. I expect the sign of the relationship to be negative, but with low statistical significance.

Population above 100,000. This is a dummy variable equal to 1 for counties with population above 100,000 . It tries to answer the question of the effect of greater population size on the demand for abortion, separating it from other similar variables 
such as population density. Previous studies have introduced geographical location variables such as far west location (Medoff, 1997) on the account that western states have generally more liberal views, although the same assumption can be made for the decision to live in more populated areas. The sign of the coefficient is expected to be positive.

Population density. This is a variable not considered in the previous studies examined. It attempts to extrapolate differences between rural and urban populations. I expect the value of the coefficient to be positive. Although population size and population density might seem to capture the same effect, they are, in my opinion, slightly different. The correlation between population and population density is 0.79 . Although positive and quite strong, the two variables are different enough to avoid the problem of multicollinearity and they will both be included in the model.

Unemployment rate. Several studies have included the unemployment rate among the explanatory variables, although some do not (Garbacz, 1990; Medoff, 2012). Medoff (1997) finds the sign of the coefficient to be negative, while Snarr and Edwards (2009) find it to be positive. In both cases the coefficient is significant at the $10 \%$ level. I expect the sign to be positive.

Percentage of minority resident. Studies that have included the percentage of minority residents as explanatory variable (Gober, 1988) find the sign of the coefficient to be positive. I expect the same results, and a relatively strong level of significance, since minority women have the greater share of abortions.

Share of Republican vote. Most studies (Medoff, 1997 and others) include a variable that tries to capture effects of conservative ideology and political leaning on abortion. It is generally found to have a negative sign of the coefficient, but sometimes 
with low significance (Garbacz, 1990). This variable tries to tie ideology with actual behavior. In a sense, it is an important variable to estimate, as often conservative leanings are associated with anti-choice sentiments. In this study I chose a method to measure conservative leanings in a way that does not rely on opinion polls but on measurable outcomes; namely statewide elections. For the year 2000 the share of Republican vote is measured using the Presidential election, and for 2010 the Senatorial election. The sign of the coefficient is expected to be negative.

Religious affiliation. As for measures of political leaning, most studies on abortion demand include variables that attempt to measure the influence of religious affiliation (Medoff, 1997, 2008; Gober, 1994). Since most mainstream religions have strong beliefs against abortion, I chose to use a measure of church affiliation, independent of denomination. Previous studies have found conflicting results for specific religious affiliation. For example, Medoff (2008) finds a negative sign for the coefficient when considering Evangelical Christians, while Gober (1994) finds a positive sign for Catholic affiliation. My expectation is a negative sign of the coefficient, but with low statistical significance.

Percentage of population on medical assistance. Although Pennsylvania law expressly forbids the use of public funds for abortion, funds exist through individual providers for women seeking pregnancy termination who obtain health insurance through the state. The coefficient of this variable is expected to be positive, as it is according to Garbacz (1990), Snarr and Jeffrey (2009), and Medoff (2012).

Percentage of births to mothers under 18. This variable is not explicitly included in the previous papers reviewed for this research, but it is worth introducing it, as it is an 
indication of local attitudes toward teen pregnancies and possibly an indicator of attitudes toward abortion. As in the case of income, there are two factors at play that push the coefficient in different directions: one as an indication of relaxed sexual mores, the other as a symptom of the local tendency of young pregnant women to carry an abortion to term with all the consequences of that choice instead of seeking a termination. I expect the sign of the coefficient to be positive.

Percentage of population below poverty level. Although superficially this variable seems to correlate with household income, having both values allows getting to a deeper level of analysis, as income distribution can play a role. The correlation for 2010 among household income and population below poverty line is -0.733 . it is negative as expected, quite strong, but so that there is no risk of multicollinearity. The sign of the coefficient is hard to predict. On the one hand, lower income women can have more trouble affording the procedure; on the other hand poverty can be correlated with less contraceptive use.

Rate of Gonorrhea infection. Sexual promiscuity and use of the most commonly used contraceptive -condoms- are hard to measure. One way is to consider the incidence of sexually transmitted diseases. The Pennsylvania Department of Health keeps track of cases and publishes information by county of people infected by specific STDs. The sign of the coefficient is expected to be positive.

Rate of women between 20 and 24. The variable was selected in accordance with Medoff's analysis as a candidate for the explanation for the counterintuitive importance of price. It attempts to incorporate demographic shifts not easily captured by other variables. For each county, I calculated the ratio of women between 20 and 24 years of age over the total number of women of childbearing age. The choice stems from the fact 
that about a third of all abortions involve women of that age group. The sign of the coefficient is expected to be positive.

Table 5: Summary statistics of the variables included in the research in 2010

\begin{tabular}{|c|c|c|c|c|c|}
\hline Variable & $\mathrm{Ob}$ & Mean & Std. Dev. & Min & Max \\
\hline Number of women 15-49 & 67 & 43775.22 & 66887.56 & 864 & 412706 \\
\hline Population above 100,000 & 67 & 0.447 & 0.501 & 0 & 1 \\
\hline Abortion rate & 67 & 5.949 & 4.970 & 0.11 & 35.69 \\
\hline Abortion ratio & 67 & 129.69 & 100.66 & 2.11 & 637.95 \\
\hline Median household income & 67 & 35940.81 & 7298.22 & 26877 & 66216 \\
\hline Unemployment rate & 67 & 8.737 & 1.314 & 6.1 & 13.7 \\
\hline Minority residents & 67 & 10.111 & 9.916 & 1.9 & 63.1 \\
\hline Share of Republican vote & 67 & 64.643 & 10.634 & 17 & 79.3 \\
\hline Religious affiliation & 67 & 48.962 & 11.53 & 29.2 & 88.7 \\
\hline Population density & 67 & 467.28 & 1434.26 & 13 & 11379 \\
\hline Pctg pop on medical assistance & 67 & 19.326 & 25.375 & 7 & 221 \\
\hline Pctg of birth to mothers under 18 & 67 & 2.425 & 1.387 & 0 & 9 \\
\hline Pctg population below poverty & 67 & 12.402 & 3.516 & 5 & 25 \\
\hline Rate of gonorrhea infection & 67 & 4.14 & 6.136 & 0 & 38.5 \\
\hline Ratio of women 20-24 & 67 & 13.89 & 4.12 & 4.3 & 33.7 \\
\hline Abortion provider & 67 & 0.164 & 0.373 & 0 & 1 \\
\hline Fertility Rate & 67 & 46.50 & 6.876 & 21.61 & 58.99 \\
\hline
\end{tabular}


Presence of an abortion provider. This dummy variable, 1 if one or more abortion providers are present in the county, is a proxy for distance. Some remote and rural counties in Pennsylvania are quite far from major centers where the service is available. As noted before, over 2000 Pennsylvania women seek an abortion in nearby states. It is possible that most of them come from rural, remote counties, where out-of-state providers are closer geographically. Nonetheless, this is an important variable, and the sign of the coefficient is expected to be positive.

Table 5 provides a summary statistics of the variables included in the analysis. Some of them have a great variation, such as income or the share of Republican vote. This fact is indication of the different realities existing in the state of Pennsylvania, which is not a homogenous state.

The variables to be included in the model are determined by the use of stepwise forward selection, to limit the inclusion only to significant determinants. 


\section{CHAPTER VI}

\section{RESULTS AND DISCUSSION}

One of the scopes of this paper is to examine the effect of the most plausible determinants of abortion demand, as measured by the abortion ratio, controlling for price and restrictive laws. Pennsylvania is a highly heterogeneous state, a fact that allows for great variations of data. The techniques used consent to cross check the results at different times and for changes over time. Variable selection methods avoid the inclusion of irrelevant variables. Nonetheless, there seems to be a lack of strong and consistent results across the regressions.

In the model, I distinguished between economic, social and behavioral factors, and I will now look at each factor separately.

As expected, and in accordance with theoretical models, income has a low effect on abortion ratio as two forces push in opposite directions, in effect annulling each other. The unemployment rate seems to have a significant positive effect in 2000 , while changes in unemployment do not appear to have any significant effect. Since Pennsylvania does not allow for state or federal funds to be used for abortions, while an increase in unemployment will on one hand reduce the ability to afford contraception and on the other also the ability to afford the procedure.

The presence of an abortion provider has a significant effect in 2000. Between 2000 and 2010 a county lost its provider, but that did not have a significant effect on the 
abortion ratio. Interestingly, an increase in the poverty rate caused a significant decrease in the abortion ratio.

Table 6: Summary results of the three regressions

\begin{tabular}{|c|c|c|c|}
\hline \multirow[b]{2}{*}{ Independent Variable } & \multicolumn{2}{|c|}{ Abortion ratio } & \multirow[b]{2}{*}{ First differencing } \\
\hline & 2000 & 2010 & \\
\hline Republican vote & $\begin{array}{l}-2.31 \mathrm{a} \\
(3.85)\end{array}$ & $\begin{array}{l}-1.37 \\
(1.41)\end{array}$ & \\
\hline Population density & $\begin{array}{l}0.036 \mathrm{a} \\
(4.94)\end{array}$ & $\begin{array}{l}0.016 \mathrm{a} \\
(2.10)\end{array}$ & $\begin{array}{l}-0.11 b \\
(1.82)\end{array}$ \\
\hline Abortion provider & $\begin{array}{l}72.20 \mathrm{a} \\
(3.89)\end{array}$ & $\begin{array}{l}30.61 \\
(1.28)\end{array}$ & \\
\hline Fertility rate & $\begin{array}{c}-0.58 \\
(0.60)\end{array}$ & $\begin{array}{l}-2.64 \mathrm{a} \\
(2.47)\end{array}$ & $\begin{array}{l}-5.32 \mathrm{a} \\
(4.30)\end{array}$ \\
\hline Rate of Gonorrhea & $\begin{array}{l}4.05 \mathrm{a} \\
(3.14)\end{array}$ & & \\
\hline Medical assistance & $\begin{array}{c}-6.42 \mathrm{a} \\
(2.90)\end{array}$ & & \\
\hline Unemployment rate & $\begin{array}{l}16.22 \mathrm{a} \\
(2.28)\end{array}$ & $\begin{array}{l}6.36 \\
(1.13)\end{array}$ & \\
\hline Median hh income & $\begin{array}{c}-0.0013 \\
(1.07)\end{array}$ & & \\
\hline Minority residents & & $\begin{array}{l}5.19 \mathrm{a} \\
(3.66)\end{array}$ & $\begin{array}{l}6.32 \mathrm{a} \\
(3.55)\end{array}$ \\
\hline Religious affiliation & & $\begin{array}{l}1.81 \mathrm{a} \\
(2.94)\end{array}$ & \\
\hline Births to mother under 18 & & $\begin{array}{c}-17.23 \mathrm{a} \\
(3.76)\end{array}$ & \\
\hline Poverty rate & & $\begin{array}{l}-4.40 \\
(1.35)\end{array}$ & $\begin{array}{l}-11.20 \mathrm{a} \\
(3.37)\end{array}$ \\
\hline Rate of women 20-24 & $\begin{array}{c}1.97 \\
(1.49)\end{array}$ & & $\begin{array}{l}10.41 \mathrm{a} \\
(2.10)\end{array}$ \\
\hline Minors living in poverty & & $\begin{array}{l}4.87 \mathrm{a} \\
(2.45)\end{array}$ & $\begin{array}{l}7.40 \mathrm{a} \\
(3.96)\end{array}$ \\
\hline Adjusted R-squared & 0.8816 & 0.8176 & 0.4865 \\
\hline
\end{tabular}

Note: Absolute value of t-statistics in parentheses

a Estimated coefficient statistically significant and the 0.01 level of significance b Estimated coefficient statistically significant and the 0.05 level of significance c Estimated coefficient statistically significant and the 0.10 level of significance 
In the category broadly defined as social factors, in which I will include demographic components, neither the share of Republican vote in statewide elections, a measure of conservative ideology nor religious affiliation, as measured the Association of Religious Data Archive, seem to be strongly related to the abortion ratio. The finding is somewhat surprising, but not unheard of, as also Medoff found the same effect for Catholic affiliation.

The main finding seems to be an across the three regressions (although with different levels of significance) negative sign of the coefficient of the fertility rate. An increase in the desire to have children appears to decrease the abortion ratio. This finding is probably the most consistent with the view of Cultural Materialism. Also, an increase in the rate of women between the age of 20 and 24 has a significant effect on the abortion ratio.

When describing variable choice, I discussed the inclusion of two variables that seem to measure similar effects: population density and the size of the county. Although the size of the county does not appear to affect the abortion ratio, population density has a positive effect when looking at individual years, but a negative effect when looking at change. When the population declines, the abortion ratio increases. Population decline is usually associated with social and economic problems, and the finding is not surprising. Since a majority of abortions are performed on minority women, it is not surprising that an increase in the minority population causes a significant increase in the abortion ratio. Behavioral effects are hard to measure, the most important of which are contraceptive use and promiscuity. I chose to use the spread of STDs, specifically gonorrhea and the percentage of births to women under 18 to account for it. Both variables are significant 
only in one of the two years considered, and changes in their rates seem to affect the abortion ratio. Measuring the effects of contraceptive use in not easy, and the need exists to find other ways to include that aspect of sexual behavior in the analysis.

In order to avoid the introduction of insignificant or low significance variables, I use a forward stepwise selection procedure, and setup the threshold for removal at 0.3 , since I am looking for a relatively high level of significance. The listed t-values in parentheses are in absolute value. The adjusted R-squared values are also listed for each regression. The adjusted R-squared values are quite high in the two OLS regressions (0.8871 in 2000 and 0.8176 in 2010), and 0.4865 in the first-difference regression, and they are generally in accordance with previous research. It appears that in the presence of constant price and legislation, only less than half of the changes in abortion ratio can be easily explained with a set of demographic, economic, and behavioral variables most commonly used.

An important aspect of economic analysis with implications for economic policy is the concept of elasticity. Elasticity of demand, for instance, measures the reaction of the quantity demanded when a determinant of demand -price being the most commonly applied and usually one of the most relevant- changes ceteris paribus -all other things being equal.

As examples of elasticity drawn from one of the models, I am going to calculate the elasticity of share of Republican vote and population density in 2000. The Republican vote in state-wide elections is measured as a percentage of the total, while abortion ratio is the number of abortions per 1000 live births. The coefficient of the regression is -2.31 which represent the change in abortion rate for a one percent change in Republican vote. 
In 2000 , the share of Republican vote was $47 \%$ while the state-wide abortion ratio was 232.4. The mean of the share of Republican vote differs from the one in table 3 , since table 3 reports the average by county with different population sizes. The elasticity calculated at those values is -0.455 ; less than one in absolute value, hence inelastic.

The coefficient for the variable population density is 0.036 , positive and significant. The elasticity of the variable in 2000 (population density for the entire state in 2000 was 274 people per square mile) is 0.042 ; an increase of one person per square mile will cause the abortion rate to increase by 0.042 . In the same manner, it is possible to calculate the values for the elasticity of each variable. 


\section{CHAPTER VII}

\section{CONCLUSION}

Abortion is a very controversial subject with wide ethical, medical, philosophical, and political ramifications. In this paper I use available data to estimate the incidence of illegal abortion in the pre-legalization era and the factors that might influence the demand for abortion in Pennsylvania in the period 2000-2010. As other researchers have done before, this research attempts to isolate and explain some of the factors that influence changes in the abortion ratio across time and geographical areas. The methods used in this paper are based on methods used in previous research with a careful use of variable selection techniques although, unlike previous literature, they are applied to county-based data for a single state. The technique allows controlling for price and legislative hurdles since they are applied across each state.

The first-difference analysis appears to stress the importance of demographic variables such as fertility rate and the rate of women age 20 to 24 as factors that have an effect on changes in the abortion rate over time, but only in conjunction with other explanatory variables.

The study finds that changes in the incidence of abortion across time and space are only in part explained by the variables selected and that the variables suffer from a measurement defect that is difficult to correct. Reliance on opinion polls and selfreporting appears not to be the answer as some findings seem to contradict commonly held ideas about ideology and behavior. Neither changes in political leanings, nor 
changes in religious attitudes appear to affect the abortion ratio. In the first case, most voters are not one-issue voters; moreover, if the voters are more willing to vote based on economic conditions rather than ideology, there is the risk of endogeneity when economic variables are part of the explanatory variables. In the case of religion, especially in small communities, religious participation is part of the social fabric and might not necessarily reflect personal ideology and beliefs or private behavior. Studies on the prevalence of the occurrence in the years before legalization indicate a certain level persistence, even in the presence of severe punishments and the possibility of social ostracism.

Since its peak in 1980, the abortion ratio and abortion ratio have steadily decreased, although in Pennsylvania the trend had stopped around the year 2000. The last few years in Pennsylvania have seen a certain increase, beginning to close the gap with the national rate, the latter being historically substantially lower. How much of the change is from measurement error is difficult to tell. Not every state is as careful in recording abortions, and the problem of interstate and international abortions adds methodological complexity to the issue.

It is not the scope of this research to discuss the broader policy implications which would require a more comprehensive approach, but the findings of this study show that the issue is not as simple and clear-cut as has been suggested. 


\section{REFERENCES}

1. Abernathy J., Greenberg B., and Horvitz D. 1970 "Estimates of Induced Abortion in Urban North Carolina." Demography, Vol. 7(1):19-29.

2. Becker, Gary. 1976 The Economic Approach to Human Behavior, Chicago, The University of Chicago Press.

3. Blank, R.M., George, C., London R. 1996 "State Abortion Rates: The Impact of Policies, Providers, Politics, Demographics and Economic Environment," Journal of Health Economics, Vol. 15: 513-553.

4. Bongaarts, J. 1978 "A Framework for Analyzing the Proximate Determinants of Fertility." Population and Development Review, Vol. 4(1): 105-132.

5. Calderone, M. 1958 Abortion in the United States, Paul B. Hoeber, New York.

6. Cates, W., Rochat, R. 1976 "Illegal Abortions in the United States: 1972-1974." Family Planning Perspectives, Vol. 8(2): 86-92.

7. Cates, W., Grimes, D., and Schulz, K. 2003 "The Public Health Impact of Legal Abortion: 30 Years Later." Perspective on Sexual and Reproductive Health, Vol. 35(1): 25-28.

8. Center for Disease Control and Prevention. 2010 "Use of Contraception in the United States: 1982 - 2010.” Vital and Health Statistics, Vol:23(29): 1-54.

9. Eckolm, E. "A Pill Available in Mexico is a Texan Option for Abortion", The New York Times, July 13 ${ }^{\text {th }}$, 2013. < http://www.nytimes.com/2013/07/14/us/inmexican-pill-a-texas-option-for-an-abortion.html?pagewanted=all\&_r=0> Accessed, June 10 $0^{\text {th }}, 2014$.

10. Foreit, K,. Nortman, D. 1992 "A Method for Calculating Rates of Induces Abortions." Demography, Vol 29(2): 127-137

11. Garbacz, Christopher. 1990 “Abortion Demand.” Population Research and Policy Review, Vol. 9(2): 151-160.

12. Gober, P. 1994 "Why Abortion Rates vary: A Geographical Examination of the Supply of and Demand for Abortion Services in the United States in 1988." Annals of the Association of American Geographers, Vol. 84(2): 230-250. 
13. Gohmann, S., Ohsfeldt, R. 1993 "Effects of Price and Availability on Abortion Demand," Contemporary Policy Issues, Vol. 11(4):42-55.

14. Gold, R. 2003 "Lessons from Before Roe: Will Past Be Prologue?" The Guttmacher Report on Public Policy, 8-11.

15. Haas-Wilson, D. 1996 "The Impact of State Abortion Restrictions on Minors Demand for Abortions," Journal of Human Resources, Vol. 31:140-158.

16. Harris-Taylor, M. "Michigan Abortion Clinics See an Influx of Ohioans", The Toledo Blade. March 23, 2014, accessed March 27, 2014, http://www.toledoblade.com/Medical/2014/03/23/Michigan-abortion-clinics-seean-influx-of-Ohioans.html

17. Henry, A. 1981 "30 Million Illegal Abortions, 10 Million Complications." Off Our Backs, Vol. 11(6): 5.

18. Harris, M. 1989 Our Kind, New York, Harper and Row Publishers Inc.

19. Harris, M. 1979 Cultural Materialism, Walnut Creek, CA. AltaMira Press.

20. Joyce, T. 2011 "The Supply-Side Economics of Abortion." New England Journal of Medicine, Vol. 365(16): 1466-1469.

21. Mccoy, T. Historian believes bodies of 800 babies, long-dead, are in a tank at Irish home for unwed mothers, The Washington Post, June $3^{\text {rd }}, 2014$. < http://www.washingtonpost.com/news/morning-mix/wp/2014/06/03/bodies-of800-babies-long-dead-found-in-septic-tank-at-former-irish-home-for-unwedmothers/> accessed, June $25^{\text {th }}, 2014$.

22. Medoff, M. 1997 "A Pooled Time-Series Analysis of Abortion Demand." Population Research and Policy review, Vol. 16(6): 597-605.

23. Medoff, M. 1998 "Estimates of the Abortion Demand of Young and Older Teenagers." Population Research and Policy Review, Vol. 17(6): 539-549.

24. Medoff, M. 2008 "The Response of Abortion Demand to Changes in Abortion Costs." Social Indicators Research, Vol. 87(2): 329-346.

25. Medoff, M. 2012 "Unintended Pregnancies, Restrictive Abortion Laws, and Abortion Demand." International Scholarly Research Network, Vol. 2012.

26. Planned Parenthood federation of America. 2006 "Report: A History of Birth Control Methods." 
27. Rossier, C. 2003 "Estimating Induced Abortion Rates: A Review." Studies in Family Planning, Vol. 34(2): 87-102.

28. Rothstein, D. 1992 "An Economic Approach to Abortion Demand." The American Economist, Vol. 3(1): 53-64.

29. Snarr, H., Edwards, J. 2009 "Does Income Support Increased Abortions?" Social Choice and Welfare, Vol. 33(4): 575-599.

30. U. S. Department of Health, Education, and Welfare. 1979 "Patterns of Aggregate and Individual Changes in Contraceptive Practice: United States, 1965 - 1975." Vital and Health Statistics, Vol. 3(17): 1-31. 